\title{
ВЛИЯНИЕ СОДЕРЖАНИЯ МОДИФИКАТОРА НА ФОТОДЕСТРУКЦИЮ И ФОТООКИСЛЕНИЕ КОМПОЗИТА НА ОСНОВЕ ПОЛИФЕНИЛЕНСУЛЬФИДА
}

\author{
В.Б. Иванов ${ }^{1}$, Е.В. Солина ${ }^{1}$, Е.В. Калугина ${ }^{2}$, А.В. Саморядов ${ }^{3}$ \\ ${ }^{1}$ ФББУН Федеральный исследовательский центр химической физики им. Н.Н. Семенова РАН, ГСП-1, ул. \\ Косыгина, 4, Москва, Российская Федерация, 119991 \\ E-mail: ivb@chph.ras.ru, elenasolina@gmail.com \\ ${ }^{2}$ Общество с ограниченной ответственностью «Группа ПОЛИПЛАСТИК», ул. Генерала Дорохова, д. 14, \\ Москва, Российская Федерация, 119530 \\ E-mail: kalugina@polyplastic.ru \\ ${ }^{3}$ ФББУН Межведомственный центр аналитических исследований в области физики, химии и биологии \\ при Президиуме РАН, ул. Профсоюзная, д. 65, стр. 6, Москва, Российская Федерация, 117342 \\ E-mail: a2612sam@yandex.ru
}

Изучено влияние спектрального состава света, температуры и содержания модификатора на образование полисопряженных структур и продуктов окисления при облучении композита на основе полифениленсульфида и сополимера этилена и глицидилетакрилата. Установлены кинетические закономерности процессов при последовательном облучении композита полным светом, моделирующим солнечный, и его длинноволновой составляющей, а также при облучении и термическом воздействии. Определены энергии активации деструкции композитов в экстремальных условиях, при одновременном воздействии света и повыщенных температур.

Ключевые слова: композит, полифенленсульфид, сополимер этилена и глицидилметакрилата, фотодеструкция, фотоокисление, фотохромизм

\section{THE EFFECT OF THE MODIFIER CONTENT ON PHOTODEGRADATION AND PHOTOOXIDATION OF A POLYPHENYLENE SULFIDE-BASED COMPOSITE}

\author{
V.B. Ivanov ${ }^{1}$, E.V. Solina ${ }^{1}$, E.V. Kalugina ${ }^{2}$, A.V. Samoryadov ${ }^{3}$ \\ ${ }^{1}$ Semenov Federal Research Center for Chemical Physics RAS, Kosygin Street, 4, Moscow, Russian Federation, \\ 119991 \\ E-mail: ivb@chph.ras.ru, elenasolina@gmail.com \\ ${ }^{2}$ Group POLYPLASTIC, LLC, Generala Dorokhova str., 14, Moscow, Russian Federation, 119530 \\ E-mail: kalugina@polyplastic.ru \\ ${ }^{3}$ Interdepartmental Center for Analytical Research in Physics, Chemistry, and Biology, Presidium RAS, \\ Profsoyuznaya Street, 65, Moscow, Russian Federation, 117342 \\ E-mail: a2612sam@yandex.ru
}

The effect of the spectral composition of light, temperature and the modifier content on the formation of polyconjugated structures and oxidation products during irradiation of composites based on polyphenylene sulfide and copolymer of ethylene and glycidyl methacrylate was studied. The kinetics behaviors of processes were determined in sequential irradiation of composites with full light that modeling sunshine and with their long-wave component as well as in irradiation and thermal action. The activation energies were evaluated for composite degradation in extremal conditions under simultaneous action of light and elevated temperatures.

Key words: composite, copolymer of ethylene and glycidyl methacrylate, polyphenylene sulfide, photodegradation, photooxidation, photochromism 
Для цитирования:

Иванов В.Б., Солина Е.В., Калугина Е.В., Саморядов А.В. Влияние содержания модификатора на фотодеструкцию и фотоокисление композита на основе полифениленсульфида. Рос. хим. ж. (Ж. Рос. хим. об-ва). 2021. T. LXV. № 3. C. 91-98

For citation:

Ivanov V.B., Solina E.V., Kalugina E.V., Samoryadov A.V. The effect of the modifier content on photodegradation and photooxidation of a polyphenylene sulfide-based composite. Ros. Khim. Zh. 2021. V. 65. N 3. P. 91-98

\section{ВВЕДЕНИЕ}

Полифениленсульфид (ПФС) характеризуется высокой тепло- и термостойкостью, химической устойчивостью к кислотам, щелочам и органическим растворителям, стойкостью к растрескиванию, низкой ползучестью и очень низким водопоглощением $[1,2]$. Благодаря этим свойствам и прекрасным электрическим характеристикам, ПФС находит широкое применение в электротехнике и электронике, а также в других отраслях промышленности [3].

Основными недостатками ПФС являются низкая светостойкость [4-8] и хрупкость, количественно характеризующаяся величиной относительно низкой ударной вязкости [7].

Высокая чувствительность ПФС к действию света наиболее наглядно проявляется в быстром изменении цвета (пожелтении) [7-10], причем это явление характерно именно для самих макромолекул ПФС. Пожелтение происходит достаточно быстро не только при облучении светом, соответствующим спектральному составу солнечного излучения или его ультрафиолетовой составляющей, но и видимым светом [7]. Наряду с накоплением полисопряженных структур, ответственных за пожелтение, наблюдается и образование кислородсодержащих групп, регистрируемых методом ИКспектроскопии, однако их содержание относительно невелико [7]. Это является основной причиной, из-за которой обычные УФ-абсорберы и антиоксиданты не способны заметно повысить светостойкость ПФС [11-12]. Удовлетворительный эффект достигнут лишь при использовании полимерного покрытия, обеспечивающего практически полное поглощение всего падающего на материал излучения [13].

Повышение ударной вязкости обеспечивается введением в композиции на основе ПФС эластомеров-модификаторов $[14,15]$, в частности, сополимера этилена с глицидилметакрилатом (СЭГМ) [14]. Естественно, что такая модификация в общем случае может изменять не только физико-механические характеристики, но и физико-химические свойства материала. При эксплуатации изделий в естественных условиях на них могут одновременно или последовательно воздействовать несколько внешних факторов, среди которых, учитывая существующие и потенциальные области применения, наиболее значимыми являются свет и повышенные температуры. Поэтому основной задачей исследования являлся анализ влияния света и тепла, а также света разного спектрального состава на деструкцию композита ПФС/СЭГМ с варьируемым в широких пределах содержанием СЭГМ. В качестве основного метода, имея в виду его высокую чувствительность и потенциал в качестве неразрушающего метода контроля, использована количественная цветометрия. Анализ процессов с участием СЭГМ осуществляли с использованием ИК-спектроскопии.

\section{ЭКСПЕРИМЕНТАЛЬНАЯ ЧАСТЬ}

В работе использован порошкообразный ПФС марки NHU-PPS Polymer 1330C (Zhejiang NHU Special Materials Co., KHP), имеющий показатель текучести расплава 250 г/10 мин $\left(316^{\circ} \mathrm{C}, 5\right.$ кг), температуру плавления $278{ }^{\circ} \mathrm{C}$, содержание летучих веществ $0,1 \%\left(150{ }^{\circ} \mathrm{C}, 1\right.$ ч) и содержание хлора - не более 1200 ppm. В качестве модификатора применяли СЭГМ марки Lotader AX8840 (Arkema, Франция), содержаний 8 масс.\% глицидилметакрилата и имеющий показатель текучести расплава 5 г/10 мин (190 ${ }^{\circ} \mathrm{C}, 2,16$ кг), плотность 0,94 г/ $\mathrm{cm}^{3}$ и температуру плавления $106^{\circ} \mathrm{C}$. Содержание СЭГМ в композите составляло 4, 10 или 20 масс.\%. Для повышения термостабильности в композит добавляли смесь бис(2,4-ди-трет-бутилфенил)пентаэритритол дифосфита (0,3 масс.\%) и N,N-гексаметиленбис[3-(3,5-ди-трет-бутил-4-гидроксифенил-пропионамида)] (0,3 масс.\%).

Образцы в виде дисков толщиной 2 мм и диаметром 50 мм получали методом литья под давлением

Определение цветометрических характеристик и спектров отражения в области 400-700 нм осуществляли с помощью спектрофотометра ColorFlex (Hunter Lab, США) в режиме: $45 / 0^{\circ}$, угол наблюдения $10^{\circ}$, источник света D65. Используемое в качестве основного критерия значение цвето- 
вого различия $\Delta \mathrm{E}$ в системе CIELab-76 [16] определяли по уравнению (1):

$$
\Delta \mathrm{E}=\left[(\Delta \mathrm{L} *)^{2}+\left(\Delta \mathrm{a}^{*}\right)^{2}+\left(\Delta \mathrm{b}^{*}\right)^{2}\right]^{1 / 2}
$$

где $\Delta L^{*}=L_{\mathrm{i}}^{*}-L_{0}{ }^{*}, \Delta a^{*}=a_{\mathrm{i}}^{*}-a_{0}{ }^{*}, \Delta b^{*}=b_{\mathrm{i}}^{*}-b_{0}^{*}$, причем индекс 0 относится в данном случае к образцу до испытаний, а индекс і - к образцу после определенного периода испытаний. Значения $\mathrm{L}^{*}$, $\mathrm{a}^{*}$ и $\mathrm{b}^{*}$ определяли непосредственно в результате измерений с использованием программного обеспечения спектрофотометра ColorFlex.

ИК-спектры в области 400-4000 см с $^{-1}$ егистрировали с использованием Фурье-спектрометра Nicolet 6700 (Thermal Electron Corp., США) с приставкой НПВО iTR ATR (Thermo Nicolet, США) в режиме накопления сигнала (1024 сканирований) при разрешении $2 \mathrm{~cm}^{-1}$. Обработку и анализ данных осуществляли с помощью программного обеспечения OMNIC.

Фотохимическое старение проводили в аппарате SUNTEST XLS+ (Atlas, CШA), оборудованном системой фильтров, обеспечивающих соответствие излучения солнечному свету в естественных условиях, в режиме: длина волны излучения больше 290 нм, общая интенсивность $500 \mathrm{BT} / \mathrm{M}^{2}$, температура черной панели 50 или $60^{\circ} \mathrm{C}$. Для выделения из общего излучения видимого света использовали светофильтр ЖС11.

Термическое старение проводили при температуре $100{ }^{\circ} \mathrm{C}$ в условиях принудительной вентиляции в низкотемпературной печи СНОЛ-3.9.3.9.3.6 / 3.5-2Н (Республика Беларусь).

\section{РЕЗУЛЬТАТЫ И ИХ ОБСУЖДЕНИЕ}

При облучении образцов композита в аппарате SUNTEST XLS+ полным светом, моделирующим солнечное излучение, наблюдается быстрое окрашивание, первоначально в светло желтый, а при более продолжительном облучении - в темножелтый и бежевый (светло-коричневый) цвет. Скорость изменения цветового различия $\Delta \mathrm{E}$, определяемого по уравнению (1), максимальна в начале облучения и постепенно снижается со временем, и величина $\Delta \mathrm{E}$ приближается к квазистационарному значению (рис. 1). Неожиданным на первый взгляд является увеличение и начальной скорости изменения $\Delta \mathrm{E}$, и ее величины, достигаемой после продолжительного облучения, при увеличении содержания СЭГМ. Ожидать следовало обратного эффекта, поскольку образование полисопряженных структур, ответственных за окрашивание, является характерным свойством ПФС. Поэтому снижение его содержания должно приводить к уменьшению и скорости, и предельного изменения $\Delta \mathrm{E}$. Наиболее естественным представляется объяснение этого явления, которое учитывает существенные различия цветометрических характеристик исходных композитов. Изначально более темный $\left(\mathrm{L}^{*}=80,30\right)$ и желтый $\left(\Delta \mathrm{b}^{*}=15,64\right)$ композит с низким содержанием СЭГМ (4 масс.\%) по сравнению с композитом, содержащим 20\% СЭГМ (L* $\left.=90,27, b^{*}=7.1\right)$ через 35 ч облучения при $60{ }^{\circ} \mathrm{C}$ также является более желтым $\left(\mathrm{b}^{*}=34,97\right)$, чем композит с высоким (20 масс.\%) содержанием СЭГМ $\left(\Delta \mathrm{b}^{*}=31,98\right)$, однако как следует из полученных данных, различие в величине $\mathrm{b}^{*}$ уменьшается почти в 3 раза $\left(\mathrm{b}^{*}=8,46\right.$ для исходных образцов и 2.99 для облученных). Аналогичные результаты для образца с содержанием СЭГМ 20 масс.\%, наряду с данными, полученными после облучения при $50{ }^{\circ} \mathrm{C}$, также свидетельствуют о достижении при длительном облучении приблизительно одинакового уровня окрашивания. Приближение к этому уровню увеличивает скорость процессов, также индуцированных светом, которые приводят к расходованию полисопряженных структур и торможению дальнейшего окрашивания материала.

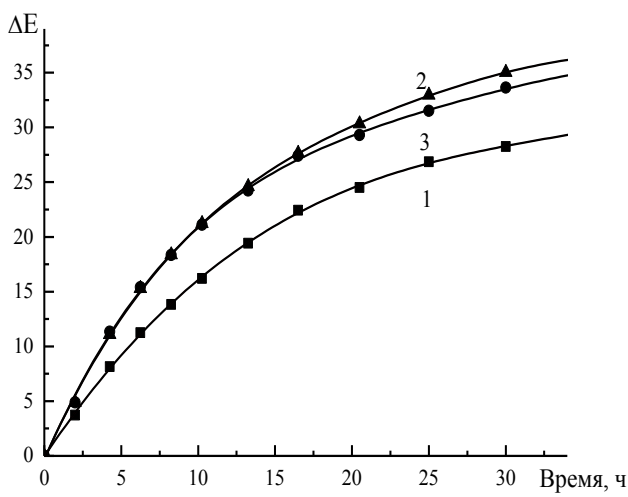

Рис. 1. Кинетические кривые увеличения цветового различия $\Delta$ Е при облучении полным светом в аппарате SUNTEST $\mathrm{XLS}+$ при $60{ }^{\circ} \mathrm{C}$ композита с содержанием СЭГМ 4 (1), 10 (2) или 20 (3) масс.\%

Более детальный анализ кинетики изменения цветометрических характеристик (рис. 2) свидетельствует о том, что в процессе облучения меняется преимущественно тон окраски, характеризующийся увеличением $\mathrm{b}^{*}$ (то есть желтизны, рис. 2 , кривые 3 и 4 ) и уменьшением L* (то есть светлоты, рис. 2, кривые 7 и 8). Величина а* незначительно возрастает, что соответствует небольшому усилению красноватого оттенка. Следовательно, именно изменение $\mathrm{L}^{*}$ и $\mathrm{b}^{*}$ вносит основной вклад в увеличение $\Delta \mathrm{E}$ (рис. 2 , кривые 1 и 2 ). 


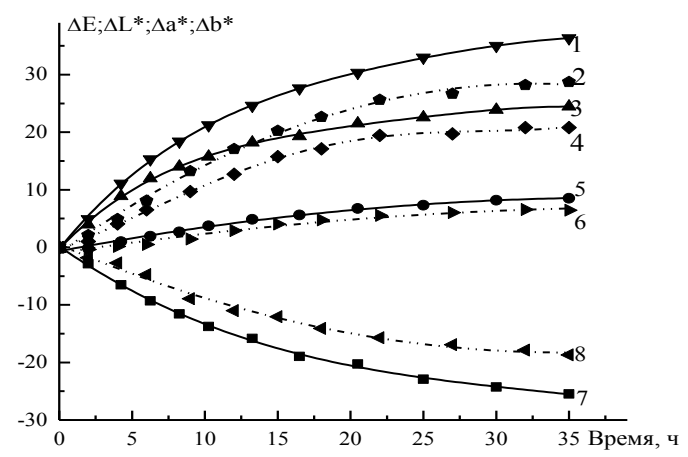

Рис. 2. Изменение цветового различия $\Delta \mathrm{E}(1,2)$ и цветометрических характеристик $L^{*}(7,8)$, $a *(5,6)$ и $b *(3,4)$ при облучении композита, содержащего $20(1,3,5,7)$ или 4 масс.\% СЭГМ $(2,4,6,8)$

Это заключение подтверждается при непосредственном анализе спектров отражения образцов (рис. 3). Видно, что при облучении полным светом коэффициент отражения $\mathrm{R}$ значительно уменьшается во всем спектральном диапазоне, но наибольшие изменения происходят в коротковолновой области, особенно в интервале 400-450 нм, соответствующему фиолетовой и синей части спектра. Важно также, что в течение всего периода облучения сохраняется близкая к линейной форма зависимости R от $\lambda$. Учитывая результаты [17] моделирования спектров полиенов, образующихся при фотодеструкции ПВХ, это позволяет считать, что функция распределения полисопряженных структур по длине цепи сопряжения является монотонной. Известно также, что коэффициенты экстинкции и максимумы поглощения полиенов возрастают с ростом длины цепи сопряжения. Следовательно, коэффициент отражения в области спектра, соответствующей максимуму поглощения полиена с данной длиной при равных концентрациях полиенов должен быть тем меньше, чем больше коэффициент экстинкции. Поэтому относительно небольшое уменьшение коэффициентов отражения в длинноволновой области, по сравнению с изменением в коротковолновой, свидетельствует о существенно более низком содержании полисопряженных структур с большой длиной цепи сопряжения в облученных образцах композита.

Отметим также, что при облучении образца с высоким (20 масс.\%) содержанием СЭГМ коэффициенты отражения меняются сильнее, чем с низким (4 масс.\%). В коротковолновой области, где масштаб влияния облучения наиболее значителен, эти изменения отличаются почти в 2 раза (54 и $29 \%$ при 400 нм). Однако и после облучения коэффициенты отражения для образца с $20 \%$ СЭГМ существенно выше, чем для образца с 4\% СЭГМ, и первый из них остается более светлым.

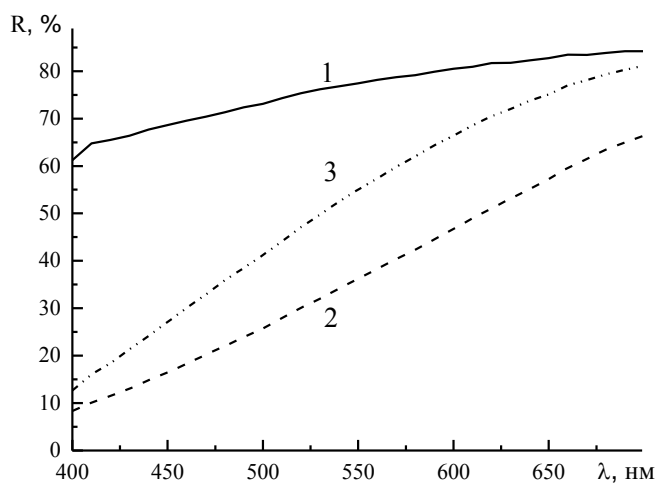

Рис. 3. Спектры отражения композита, содержащего 20 масс.\% СЭГМ до облучения (1), после облучения полным светом в течение 35 ч (2) и после дополнительного облучения светом с $\lambda>410$ нм, выделяемым из полного излучения с помощью дополнительного светофильтра ЖС11 (3)

Выше уже подчеркивалось, что окрашивание вследствие образования полисопряженных структур является характерным свойством самих макромолекул ПФС, и что эти структуры могут и сами участвовать в фотохимических процессах, что может приводить к изменению окраски материала [7]. Следовательно, эти процессы в той или иной степени должны реализовываться и в смесях ПФС с другими полимерами. Интерес представляет только выявление масштаба эффекта. И действительно, оказалось, что при облучении композитов ПФС/СЭГМ светом с $\lambda>410$ нм, выделяемым из общего излучения аппарата SUNTEST $\mathrm{XLS}+$ с помощью дополнительного светофильтра, наблюдается уменьшение цветового различия $\Delta \mathrm{E}$ по сравнению со значением, регистрируемым после длительного облучения полным светом. Эффект выражен тем сильнее, чем выше содержание СЭГМ в композите, при этом скорость процесса максимальна в начале облучения и постепенно снижается. Это представляется вполне естественным, учитывая двойное действие света, в том числе и видимого, который может вызывать не только расходование, но и образование полисопряженных структур [7]. Поэтому полное расходование полисопряженных структур не достигается и $\Delta \mathrm{E}$ постепенно приближается к новому квазистационарному значению. Как и при облучении полным светом, минимальная скорость изменения $\Delta \mathrm{E}$ регистрируется для образца с содержанием СЭГМ 4 масс.\%. 
Детальный анализ изменения цветометрических характеристик $\mathrm{L}^{*}, \mathrm{a}^{*}$ и $\mathrm{b}^{*}$ при облучении видимым светом свидетельствует о преимущественном изменении $\mathrm{L}^{*}$, в то время как $\mathrm{a}^{*}$ и $\mathrm{b}^{*}$ меняются в гораздо меньшей степени (рис. 4). Это фактически означает, что при облучении видимым светом меняется характер распределения длины сопряжения полисопряженных структур. Действительно, как показано на рис. 3, при облучении видимым светом увеличение коэффициента отражения в длинноволновой области существенно превосходят аналогичные изменения в коротковолновой области. Очевидно, это связано с преимущественным расходованием полисопряженных структур с большой длиной сопряжения, поглощающих в длинноволновой области спектра. Необходимо отметить также, что коэффициент отражения R для образца с содержанием СЭГМ 20 масс.\% (рис. 3, кривая 3) во всем диапазоне длин волн возрастает сильнее, чем для образца с содержанием 4 масс.\% . И это определяет более масштабное изменение светлоты L*, представленное на рис. 4.

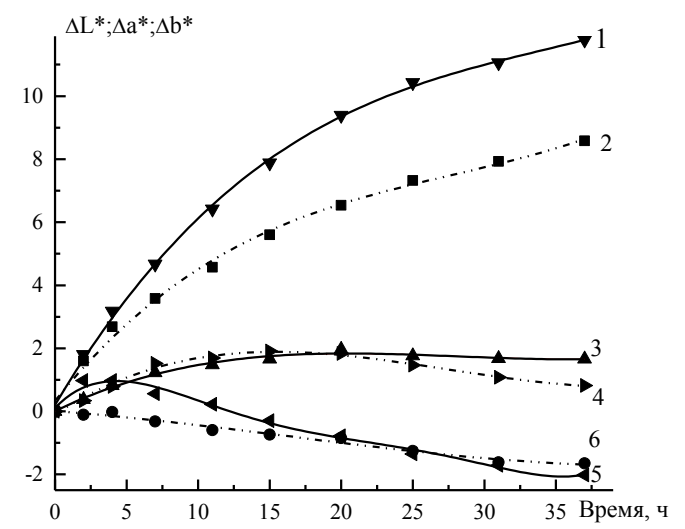

Рис. 4. Изменение цветовых характеристик $L^{*}(1 ., 2), a^{*}(3,4)$ и b* $(5,6)$ композита, содержащего $20(1,3,5)$, или 4 масс.\% СЭГМ $(2,4,6)$, при облучении видимым светом после предварительного воздействия полного излучения в аппарате SUNTEST XLS+

При эксплуатации изделий в естественных условиях умеренного и холодного климата температура окружающей среды, как правило, намного ниже рекомендуемой для испытаний международными стандартами (ISO 4892-2, температура воздуха $38^{\circ} \mathrm{C}$, температура черной панели $\left.60{ }^{\circ} \mathrm{C}\right)$. Поэтому анализ влияния температуры на фотодеструкцию композитов ПФС имеет не только научное, но и определенное практическое значение.
При изучении деструкции образцов композита с разным содержанием СЭГМ при температуре $50{ }^{\circ} \mathrm{C}$ обнаружено, что по сравнению с аналогичными результатами, полученными при $60{ }^{\circ} \mathrm{C}$ (рис. 1), кинетические кривые изменения $\Delta \mathrm{E}$ имеют два принципиальных отличия: (1) при $50{ }^{\circ} \mathrm{C}$ имеются небольшие индукционные периоды, $\sim 1$ ч; (2) уровни изменения $\Delta \mathrm{E}$, достигаемые после продолжительного облучения при $50{ }^{\circ} \mathrm{C}$ значительно ниже, чем при $60{ }^{\circ} \mathrm{C}$ (на 26\% и на 21-22\% при содержании СЭГМ 4 и 10 или 20\%).

Кинетические особенности процессов при разных температурах не позволяют однозначно определить энергии активации накопления полисопряженных структур. Для качественной оценки целесообразно сравнить максимальные скорости $\left(\mathrm{V}_{\max }\right)$ изменения цветового различия $\Delta \mathrm{E}$ при $50{ }^{\circ} \mathrm{C}$ вблизи области перегиба кинетических кривых со скоростями $\mathrm{V}_{60}$ в близком интервале изменений $\Delta \mathrm{E}$ при $60{ }^{\circ} \mathrm{C}(5 \leq \Delta \mathrm{E} \leq 10)$. При этих условиях энергию

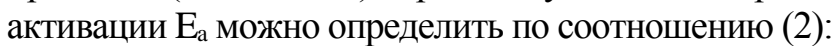

$$
E_{a}=R\left[\left(T_{1} T_{2}\right) /\left(T_{2}-T_{1}\right)\right] l k_{a}
$$

где $\mathrm{k}_{\mathrm{a}}$ - коэффициент ускорения при увеличении температуры $\mathrm{T}$, в данном случае от $\mathrm{T}_{1}=323 \mathrm{~K}$ до $\mathrm{T}_{2}=333 \mathrm{~K}, \mathrm{k}_{\mathrm{a}}=\mathrm{V}_{60} / \mathrm{V}_{\max }$, a $\mathrm{R}$ - универсальная газовая постоянная.

Рассчитанная по уравнению (2) величина $\mathrm{E}_{\mathrm{a}}$ для композита, содержащего 4 масс.\% СЭГМ, составляет 35 кДж/моль, а для образца с 20\% СЭГМ - 49 кДж/моль. Первое из этих значений соответствует оценкам энергии активации фотодеструкции ПФС в отсутствие эластомера (16-39 кДж/моль, в зависимости от степени конверсии, оцениваемой по величине $\Delta \mathrm{E}$ ) [7]. Относительно большая величина при более высоком содержании СЭГМ может свидетельствовать о значительном вкладе процессов с участием СЭГМ, так как для полиолефинов, например, энергия активации фотодеструкции составляет 50-70 кДж/моль из-за значительного вклада вторичных термических процессов. Отметим, что относительно большие для фотохимических процессов энергии активации, определены и для цветных и белых композиций на основе пластифицированного ПВХ [18], деструкция которых также включает реакции образования и расходовании полисопряженных структур.

Об участии в окислении СЭГМ свидетельствует изменение спектров НПВО после облучения композитов (рис. 5). При облучении полным светом наиболее значительно увеличиваются полосы поглощения в области 1050-1250 (С-О группы), 1350-1450 ( $\mathrm{SO}_{2}$ и $\mathrm{C}-\mathrm{O}$ группы), 1710-1730 (C=O

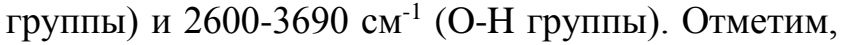


что при облучении в аналогичных условиях ПФС в отсутствие эластомеров значительные изменения происходили только в области 2600-3690 см ответствующей поглощению агрегатов О-Н групп, участвующих в образовании водородных связей.
Важно также, что полосы поглощения кислородсодержащих групп у композита с большим содержанием СЭГМ (20 масс.\%) увеличиваются более значительно, чем у композита с 4 масс.\% СЭГМ. Эти факты можно рассматривать как однозначное доказательство окисления СЭГМ под действием света.

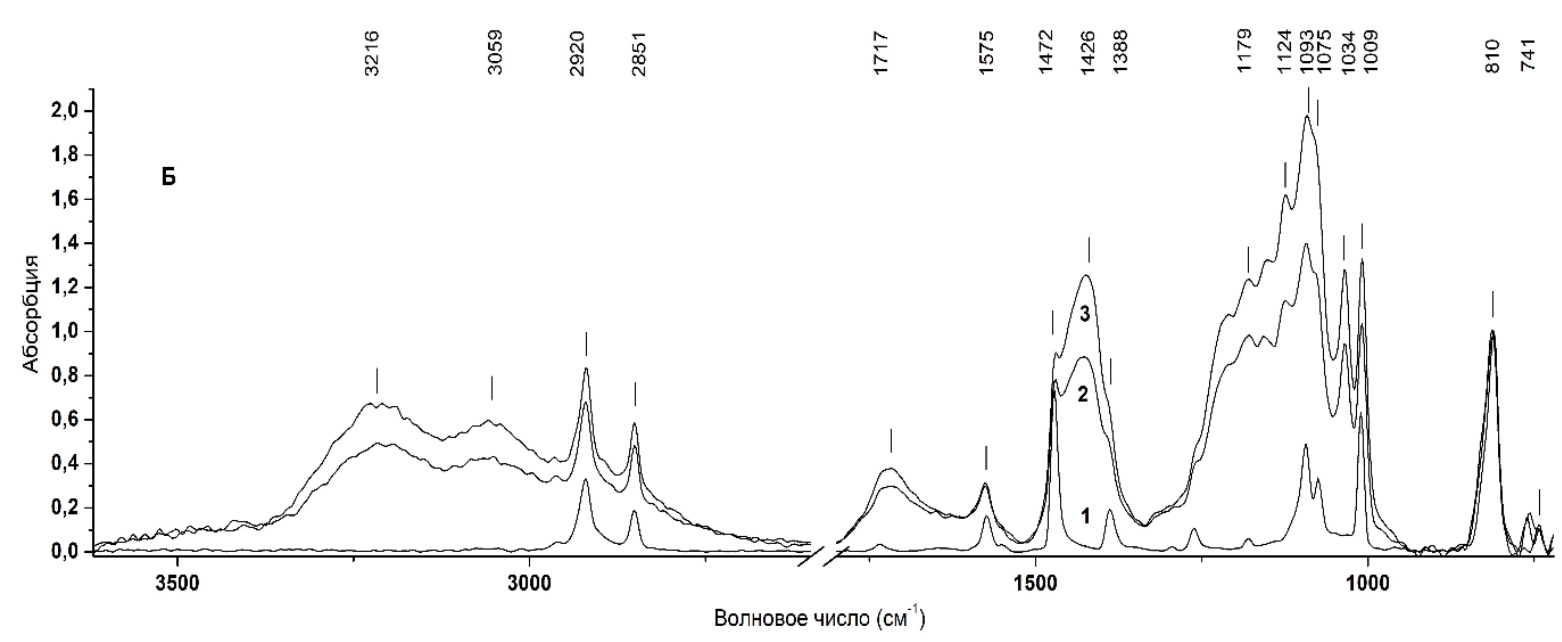

Рис. 5. Спектры НПВО композита с содержанием 20 масс.\% СЭГМ до облучения (1), после облучения полным светом при температуре $50{ }^{\circ} \mathrm{C}$ в течение 37 ч (2) и после дополнительного облучения при той же температуре видимым светом с $\lambda>410$ нм в течение 20 ч (3)

При последующем облучении композитов видимым светом, выделяемым из общего излучения аппарата SUNTEST XLS+ с помощью дополнительного светофильтра, практически все полосы, образовавшиеся при первичном облучении полным светом, значительно усиливаются (ср. спектры 2 и 3 на рис. 5). Как показано выше, в этих условиях происходит расходование полисопряженных структур, приводящее к уменьшению интенсивности окраски образцов. Одновременное увеличение полос в области 2600-3690 $\mathrm{cm}^{-1}(\mathrm{O}-\mathrm{H}$ группы), как и при облучении ПФС в отсутствие СЭГМ, свидетельствует об окислении полисопряженных структур. Неожиданным является увеличение полос поглощения в области 1050-1250 и $1350-1450 \mathrm{~cm}^{-1}$, которые в ПФС без модификатора практически отсутствовали, и которые отнесены выше к продуктам окисления СЭГМ и ПФС. Так как ни сам СЭГМ, ни продукты его окисления видимый свет не поглощают, увеличение степени окисления СЭГМ в этих условиях следует связать с инициирующим действием свободных радикалов, образующихся в процессе фотоокисления полисопряженных структур ПФС. В других условиях, например, при облучении полным светом или его УФ-составляющей, возможен и обратный эф- фект, когда радикалы, образующиеся при окислении СЭГМ будут инициировать окисление и расходование полисопряженных структур СЭГМ. Таким влиянием, по-видимому, можно объяснить относительно низкую скорость накопления полисопряженных структур при облучении композита, содержащего 20 масс.\% СГЭМ и совпадение кинетических кривых при содержании СЭГМ 10 и 20 масс.\% (рис. 1, кривые 2 и 3). Существенное затрагивание СЭГМ при фотодеструкции композита дает возможность полагать, что для повышения светостойкости целесообразно использовать фотохимически стабильные и (или) не поглощающие свет антиоксиданты $[19,20]$, особенно пространственно затрудненные амины, являющиеся наиболее эффективными светостабилизаторами полиолефинов, а также синергические смеси антиоксидантов с УФабсорберами [21].

Действие видимого света приводит к расходованию полисопряженных структур, поглощающих в видимой области спектра, наиболее сильно в его длинноволновой части (рис. 3). Естественно предположить, что эти структуры образуются из предшественников - структур с меньшей длиной сопряжения, поглощающих только в УФ-области. В этом случае активация таких предшественников, 
например, термически, должна приводить к образованию структур, поглощающих в видимой области. И действительно, такой эффект обнаружен. Прогрев при невысокой температуре предварительно облученных видимым светом образцов приводит к существенному усилению окраски, количественно регистрируемому по увеличению $\Delta \mathrm{E}$ по сравнению со значением, измеренным непосредственно после облучения. Основное изменении происходит в первые 0.5 ч $(5 \leq \Delta \mathrm{E} \leq 9)$, а далее цвет меняется слабо $(\Delta \mathrm{E} \approx 1)$. Наиболее значительный вклад в увеличение $\Delta \mathrm{E}$ вносит изменение $\mathrm{b}^{*}$, существенно меньший - $\mathrm{a}^{*}$, в то время как светлота $\mathrm{L}^{*}$ меняется незначительно. Увеличение $b^{*}$, количественно характеризует образование полисопряженных структур, поглощающих в коротковолновой части видимой области, a $\mathrm{a}^{*}$ - структур с более длинной цепью сопряжения, поглощающих в средней части видимой области. Следовательно, практически одновременно образуется набор структур с разной длиной сопряжения. Однако их распределение вполне «обычное»: содержание тем больше, чем короче длина цепи сопряжения.

Небольшое время и невысокая температура $\left(100{ }^{\circ} \mathrm{C}\right)$, при которой термодеструкция ПФС протекает с весьма малой скоростью [7], дают возможность полагать, что энергия активации процесса увеличения длины сопряжения относительно невелика, и, во всяком случае, значительно меньше энергии активации термодеструкции ПФС (119 кДж/моль, [7]). В этом смысле для ПФС характерны те же закономерности, что и для ПВХ [22-24].

Изменение содержания полисопряженных структур и связанное с этим изменение окраски при термообработке фотохимически частично обратимо: при повторном облучении образцов видимым светом величина $\Delta \mathrm{E}$ уменьшается и образцы светлеют. Эти циклы прогрев/облучение, как и циклы облучение полным светом/облучение видимым светом можно повторять, по крайней мере, несколько раз.

Таким образом, композит ПФС/СЭГМ проявляет не только обычный фотохромизм, но и так называемый обратный фотохромизм. В последнем случае при действии света на окрашенный образец происходит его обесцвечивание, а окраска восстанавливается термически. Это явление, как и фотохромизм при изменении спектрального состава света, надо учитывать при ускоренных испытаниях и прогнозировании устойчивости композитов.

\section{ЗАКЛЮЧЕНИЕ}

Окрашивание композита ПФС/СЭГМ фотохимически частично обратимо и может усиливаться или ослабляться при периодическом воздействии полного излучения, моделирующего солнечное, или его видимой составляющей (фотохромизм).

Изменение окраски частично обратимо и при периодическом воздействии видимого света и тепла (обратный фотохромизм) В этом случае облучение приводит к обесцвечиванию, а последующая термообработка - к увеличению интенсивности окраски.

Под действием света происходит также окисление компонентов композита. Для ПФС образование кислородсодержащих продуктов обусловлено преимущественно окислением полисопряженных структур. Этот процесс ограничивает предельное содержание таких структур и является причиной изменения цветовых характеристик при последующем облучении видимым светом. Кроме того, он индуцирует окисление СЭГМ, которое, в свою очередь, может инициировать окисление полисопряженных структур.

Температура испытания светостойкости сильно влияет и на скорости накопления полисопряженных структур, и на их квазистационарные концентрации. Энергия активации деструкции при содержании 4 масс.\% СЭГМ составляет 35 кДж/моль, а при 20 масс.\% СЭГМ - 49 кДж/моль.

Количественную цветометрию целесообразно использовать в качестве дополнительного метода неразрушающего контроля светостойкости композитов ПФС/СЭГМ, однако при количественной оценке степени деструкции необходимо учитывать возможное влияние фотохромизма.

Авторы выражают благодарность С.В. Усачеву за помощь в регистрации и анализе ИК-спектров.

\section{ЛИ Т Е Р А Т У Р А \\ REFERENCES}

1. Lopez L.C., Wilkes G.L. Journal of Macromolecular Science: Polymer Reviews. 1989. V. 29. N 2. P. 83-151.

2. Михайлин Ю.А. Термоустойчивые полимеры и полимерные материалы. СПб.: Профессия. 2006. 624 с. Mikhailin, $Y u$.A. Termoustoichivye polimery i polimernye materialy. Sankt-Peterburg: Professiya, Russia, 2006 (in Russian).

3. Rahate A.S., Nemade K.R., Waghuley S.A. Reviews Chemical Engineering. 2013. V. 29. P. 471-489.

4. Smmazçelik T. Materials and Design. 2006. V. 17. P. 270-277.

5. Yu Z., Li L., Meng S., Chen L., Zhu M. Progress in Natural Science: Materials International. 2015. V. 25. P. 310-315.

6. Mahat K.B., Alarifi I., Alharbi A., Asmatulu $R$. Macromolecular Symposia. 2016. V. 365. P. 157-168. 
7. Ivanov V.B., Bitt V.V., Solina E.V., Samoryyadov A.V. Polymers. 2019. 1579.

8. Ivanov V.B., Solina E.V., Samoryadov A.V. Polymer Science. D. 2020. V. 13. N 3. P. 353-357.

9. Das P.K., DesLauriers P.J., Fahey D.R. Polymer Degradation and Stability. 1995. V. 48. N 1. P. 11-23.

10. DesLauriers P.J., Gelbel J.F., Das P.K. Angewandte Makromolekulare Chemie. 1997. V. 247. N 1. P. 45-59.

11. Das P.K., DesLauriers P.J., Fahey D.R., Wood F.K., Cornforth F.J. Polymer Degradation and Stability. 1995. V. 48. N 1. P. $1-10$.

12. Zhang X.Z., Zhang K., Zhou Z., Chen L., Chen Y. Procedia Engineering. 2012. V. 27, P. 1354-1358.

13. Yang X., Duan L., Ran X. Polymer Bulletin. 2017. V. 74. N 3. P. 641-656.

14. Samoryadov A.V., Kalugina E.V., Usenko E.S. Bull. Izobret. 2021. 4 (in Russian).

15. Steffen R., Meir M., Rekstad J., Röder B. Polymer. 2018. V. 136. P. 71-83.

16. CIE 15.32004. CIE Technical report: Colorimetry: Third Ed. P. 17.
17. Zuravlev M.A., Ivanov V.B. European Polymer Journal. 1989. V. 25. N 4. P. 391-394.

18. Ivanov V.B., Solina E.V. Polymer Science. D. 2019. V. 12. N 1. P. $100-104$.

19. Ivanov V.B., Shlyapintokh V.Ya. Polymer Degradation and Stability. 1990. V. 28. N 3. P. 249-273.

20. Rozantsev E.G., Kagan E.S., Sholle V.D., Ivanov V.B., Smirnov V.A. ACS Symposium series. 1985. V. 280. P. 11.

21. Ivanov V.B., Rozenboim N.A., Angert L.G., Shlyapintokh V.Ja. Doklady Akademii Nauk SSSR. 1978. V. 241. N 3. P. 609.

22. Gumargalieva K.Z., Ivanov V.B., Zaikov G.E., Moiseev Ju.V., Pokholok T.V. Polymer Degradation and Stability. 1996. V. 52. N 1. P. 73-79.

23. Ivanov V.B., Zuravlev M.A. Polymer Photochemistry. 1986. V. 7. N 1. P. 55-64.

24. Ivanov V.B., Solina E.V., Staroverova O.V., Popova E.I., Lazareva O.L., Belova O.A. Russian Journal of Physical Chemistry. B. 2017. V. 11. N 6. P. 978-984.

Поступила в редакииюо (Received) 01.08.2021

Принята к опубликованию (Accepted) 03.09.2021 